\title{
GAMIFICAÇÃO EM ESPAÇOS DE CONVIVÊNCIA HÍBRIDOS E MULTIMODAIS: DESIGN E COGNIÇÃO EM DISCUSSÃO
}

\author{
Eliane Schlemmer*
}

\begin{abstract}
RESUMO
O artigo emerge da pesquisa Gamificação em Espaços de Convivência Hibridos e Multimodais: uma Experiência no Ensino Superior ${ }^{1}$ e objetiva compreender e discutir a relação design-cognição na docência, num contexto de configuração de Espaços de Convivência Híbridos e Multimodais, na perspectiva da Gamificação. A pesquisa, de natureza exploratória e abordagem qualitativa, usa como metodologia Design Research e cartografia, e como instrumentos: observação, registros fotográficos digitais, registros em filmadoras digitais, registros em áudio digital e registros escritos. Para a análise dos dados utiliza a análise textual discursiva. Os principais resultados evidenciam que a relação design-cognição na docência ocorre na medida em que o docente está sujeito construtor ativo do design da experiência, sendo fundamental para que atribua sentidos a uma prática inovadora, por "estar na situação" e, portanto, poder falar "de dentro", a partir do seu processo de aprendizagem. Assim, como conclusão é possível dizer que a relação design-cognição na docência, principalmente vinculada à configuração de Espaços de Convivência Híbridos e Multimodais na perspectiva da Gamificação, ocorre na medida em que o docente configura, juntamente com os discentes, esses espaços de convivência, em que o outro é reconhecido como legítimo na interação e, portanto, alguém com quem se pode aprender.
\end{abstract}

Palavras-chave: Gamificação. Espaços de convivência híbridos e multimodais. Design. Cognição. Docência.

\section{ABSTRACT}

\section{GAMIFICATION IN MULTIMODAL HYBRID LIVING SPACES: DESIGN AND COGNITION IN DISCUSSION}

The paper emerges from the research "GAMIFICATION IN HYBRID AND MULTIMODAL LIVING SPACES: AN EXPERIENCE IN HIGHER EDUCATION" and its aim is to understand and discuss the relationship between design and cognition in teaching, in a context of Hybrid and Multimodal Living Spaces, from the perspective of Gamification. The research is based on an exploratory and qualitative approach, according to the Design Research and Cartography methodology, having as instruments: observation, digital photographic records, digital video records, digital audio records and written records. Data analysis is based on discursive textual analysis. The main results show that the relationship between design and cognition in teaching occurs when the teacher is an active builder subject of the design of the experience and it is fundamental to put meanings to an innovative practice, once "being in the situation", the teacher

\footnotetext{
$\overline{1 \text { Pesquisa financiada pelo CNPq. }}$.
}

*Doutora em Informática na Educação pela Universidade Federal do Rio Grande do Sul (UFRGS). Professora-Pesquisadora Titular do Programa de Pós-Graduação em Educação da Universidade do Vale do Rio dos Sinos (UNISINOS). Endereço Institucional: Universidade do Vale do Rio dos Sinos. Av. Cristo Rei, 950 - Cristo Rei. São Leopoldo-RS. CEP: 93022-000.elianes@unisinos.br 
is able to speak "according to his/her own experience", from his/her own learning process. So, we have come to the conclusion that the design-cognition relationship in teaching, mainly linked to the Hybrid and Multimodal Living Spaces configuration, in the perspective of Gamification, occurs when the teacher configure with the students these living spaces, recognizing each other as legitimate in the interaction and therefore recognizing each student as someone from whom they can learn something.

Keywords: Gamification. Hybrid and Multimodal Living Spaces. Design. Cognition. Teaching

\section{Contextualização}

O viver e o conviver ocorrem, cada vez mais, em contextos híbridos e multimodais, onde diferentes tecnologias analógicas e digitais integram espaços presenciais físicos e online, constituindo novos espaços para o conhecer. É nesses novos espaços que os sujeitos, em movimentos nômades, interagem, constroem conhecimentos e aprendem, o que nos faz pensar que uma nova cultura possa estar emergindo, não dicotômica entre a cultura analógica e a digital, mas, sim, uma cultura que coloca esses elementos e sujeitos em relação, na perspectiva de coexistência. A essa cultura poderíamos denominar "Cultura do hibridismo e da multimodalidade", ou ainda "Cultura ubíqua", se consideramos o fato de que as pessoas, os lugares e as coisas (objetos) podem estar interligados por redes de comunicação que possibilitam o tráfego de dados entre diferentes dispositivos e redes espalhadas por prédios, ruas, carros, enfim, por toda parte, possibilitando a comunicação entre esses diferentes atores, de forma que a computação se torna praticamente invisível (SACCOL; SCHLEMMER; BARBOSA, 2010).

Nesse viver e conviver, desde os tempos primitivos, o jogo está presente e tem sido estudado enquanto elemento do desenvolvimento humano (PIAGET, 1964), presente na raiz da cultura (VYGOTSKY, 1994). De acordo com Huizinga (1993, p. 10-16, grifo do autor) o jogo "é função de vida [...] atividade livre, conscientemente tomada como 'não-séria' e exterior à vida habitual, mas ao mesmo tempo capaz de absorver o jogador de maneira intensa e total". Nesse contexto, Papert (1994), ao apresentar a parábola de um grupo de professores viajantes do tempo, comenta que eles encontraram, nas salas de aula, muita familiaridade com o que haviam vivenciado há 100 anos, no entanto, teriam muitas surpresas se tivessem ido para a casa com um ou dois dos estudantes, pois lá teriam descoberto que,

[...] com uma diligência e vivacidade que a escola raramente consegue gerar, muitos estudantes tornaram-se intensamente envolvidos em aprender as regras e estratégias do que pareceu, à primeira vista, ser um processo muito mais exigente do que qualquer tarefa de casa. Eles definiram a disciplina como "videogame" e o que estavam fazendo como 'brincando'. (PAPERT, 1994, p. 11, grifo do autor).

Vinculado ao mundo dos games, surge o conceito de gamificação, que consiste em utilizar elementos presentes na mecânica dos games, estilos de games e forma de pensar dos games em contextos não game, como forma de resolver problemas e engajar os sujeitos. Esse conceito tem sido apropriado pela área da educação, possibilitando a construção de situações de ensino e de aprendizagem capazes de engajar os sujeitos, de forma prazerosa, na definição e resolução de problemas, contribuindo para repensar o contexto educacional formal.

Assim, investigar a relação design-cognição a fim de compreender que "projeto cognitivo" emerge na construção de espaços de convivência híbridos ${ }^{2} \mathrm{e}$ multimodais $^{3}$ na perspectiva da gamificação, configura a problemática a ser discutida nesse artigo. $\mathrm{O}$ objetivo está em compreender e discutir a relação design-cognição na docência, nesses contextos.

$\mathrm{O}$ artigo está vinculado à pesquisa intitulada Gamificação em Espaços de Convivência Híbridos e Multimodais: uma Experiência no Ensino Superior,(SCHLEMMER, 2013) financiada pelo $\mathrm{CNPq}$, tendo como lócus a atividade acadêmica "Cognição em Jogos Digitais".

2 Que integram tecnologias digitais e analógicas.

3 Envolvendo as modalidades presencial física e digital virtual - mobile learning, immersive learning e ubiquitous learning. 


\section{Atividade Acadêmica Cognição em Jogos Digitais: o lócus da pesquisa}

"Cognição em Jogos Digitais" é uma atividade acadêmica optativa, de $60 \mathrm{~h}$, que integra o currículo do curso superior de Tecnologia em Jogos Digitais, da Universidade do Vale do Rio dos Sinos (UNISINOS). A atividade foi ofertada no primeiro semestre de 2014, na qual se matricularam 28 estudantes, todos do sexo masculino, com idades entre 18 e 37 anos. A atividade objetiva desenvolver competências que possibilitem ao sujeito: utilizar os conceitos dos principais mecanismos cognitivos e sociocognitivos no contexto dos jogos digitais e da gamificação; utilizar elementos do método cartográfico de pesquisa para o desenvolvimento de jogos digitais e situações gamificadas; desenvolver processos de gamificação, na relação com as concepções epistemológicas; estabelecer relações entre os tipos de interfaces dos jogos digitais e de gamificação e possibilidades de interação para o desenvolvimento de processos cognitivos e sociocognitivos; estabelecer relações entre a teoria, a experimentação enquanto sujeito que conhece e as possibilidades oferecidas em jogos digitais e situações gamificadas; articular diferentes conhecimentos relacionados ao desenvolvimento de jogos digitais e a gamificação, na realização de projetos de aprendizagem.

A proposta metodológica da atividade é inspirada no método cartográfico de pesquisa, enquanto prática pedagógica, e na gamificação, associados à metodologia de projetos de aprendizagem adaptada ao ensino superior (SCHLEMMER, 1999, 2001, 2002, 2005; SCHLEMMER; TREIN, 2009), na vinculação com os conceitos de Flipped Classroom e $\mathrm{BYOD}^{4}$, na perspectiva da construção de espaços de convivência híbridos e multimodais. A metodologia prevê ainda seminários com a participação de especialistas, de acordo com a temática abordada, desafios e o desenvolvimento dos projetos de aprendizagem.

A avaliação é da aprendizagem, priorizando a compreensão e o caráter formativo. As sucessivas

4 BYOD - Bring Your Own Devices - traga seu próprio dispositivo - é uma tendência que surge do mundo mobile e, no campo da educação, propõe dar liberdade para que os estudantes possam trazer e usar seus próprios dispositivos móveis no contexto educacional. produções de cada sujeito são acompanhadas/avaliadas em termos de qualidade crescente. A seguir apresento o contexto teórico-metodológico para o desenvolvimento da pesquisa.

\section{Contexto teórico-metodológico}

\section{Aprendizagem}

Nas Ciências Cognitivas, há inúmeras teorias que buscam explicar como o ser humano aprende, entre elas está o interacionismo-construtivista de Jean Piaget e o interacionismo-sistêmico de Humberto Maturana e Francisco Varela.

Para Piaget (1972), a aprendizagem, em geral, é provocada por situações externas e ocorre somente quando há, da parte do sujeito, uma assimilação ativa. "Toda a ênfase é colocada na atividade do próprio sujeito, e penso que sem essa atividade não há possível didática ou pedagogia que transforme significativamente o sujeito" (PIAGET, 1972, p. 11). Piaget (1972) destaca a importância da ação do sujeito para a aprendizagem, atribuindo a ele a responsabilidade pelo processo. Assim, caso não haja no processo educativo espaço para que o sujeito possa agir sobre o objeto de conhecimento, a fim de que possa compreendê-lo, dificilmente ocorrerá aprendizagem capaz de transformar esse sujeito. Nessa concepção o conhecimento é construído pelo sujeito que age sobre o objeto percebido interagindo com ele, sendo as trocas sociais condições necessárias para o desenvolvimento do pensamento. Para Piaget (1972) não há um conhecimento impessoal, ou seja, independente daquele que conhece, pois o conhecimento como tal não existe, mas somente pessoas em relação ao que conhecem.

Para Maturana (1998), a aprendizagem é o ato de transformar-se em um meio particular de interações recorrentes. "A aprendizagem ocorre quando a conduta de um organismo varia durante sua ontogenia, de maneira congruente com as variações do meio, o que faz seguindo um curso contingente nas suas interações com ele" (MATURANA, 1998, p. 31). Segundo Maturana e Rezepka (2000), todos os seres humanos, a não ser em situações extremas de alterações neurológicas, são igualmente capazes de aprender, e a forma como aprendem é própria da sua condição humana, pois são autônomos e 
autopoiéticos, ${ }^{5}$ em congruência com o meio no qual se encontram inseridos. Esta congruência com o meio pode provocar perturbações na estrutura dos seres humanos, que promoverão os processos de aprendizagem na medida em que a estrutura se autoproduzir para compensar a perturbação. Assim, de acordo com Maturana e Varela (2002), a cognição é a ação efetiva, é o processo de acoplamento estrutural no qual faz emergir as interações com o mundo interno e externo. O processo de cognição consiste na criação de um campo de comportamentos através da conduta dentro do seu domínio de interações. $\mathrm{O}$ que nós observadores entendemos por conhecimento é o que consideramos como ações (comportamentos, pensamentos, reflexões...) adequadas naquele contexto e domínio, e validadas de acordo com o nosso critério de aceitabilidade. Maturana e Varela (1997) referem que viver é conhecer e conhecer é viver, de forma que cada sujeito tem sua própria trajetória, traduzida pelos acoplamentos que realiza no seu viver e conviver.

Varela (2005) apresenta ainda os conceitos de "sí emergente" e "enação". Para o autor, interpretação e conhecimento são resultados emergentes (no sentido de emergir) da ação-no-mundo ou atuação. De forma que, a maior capacidade da cognição vivente consiste em grande medida em fazer as questões relevantes que vão surgindo em cada momento da nossa vida. Essas não são predefinidas, mas sim enatuadas: emergem da ação-no-mundo (atuação) e o relevante é o que nosso sentido comum julga como tal, sempre dentro de um contexto. Assim, conhecedor e conhecido, sujeito e objeto, se determinam um ao outro e surgem simultaneamente. A orientação enativa propõe um caminho intermediário para transcender ambos os extremos: sujeito e objeto se definem mutuamente e são correlativos.

Assim, para Varela (2005), a cognição é ação efetiva: história do acoplamento estrutural que enatua (faz emergir) um mundo, sendo que essa ocorre através de uma rede de elementos interconectados capazes de mudanças estruturais durante a história

\footnotetext{
5 "La palabra autopoiesis viene de los vocablos griegos autos, que quiere decir sí mismo, y poiesis, que quiere decir producir. Al caracterizar a los seres vivos como sistemas autopoiéticos estamos diciendo que los seres son sistemas que se caracterizan como sistemas que se producen a sí mismo continuamente" (MATURANA, 1999, p. 93)
}

ininterrupta do viver. O ponto central da cognição é a sua capacidade de fazer emergir significados, o que implica em regularidades que emergem das próprias atividades cognitivas. Assim, a cognição não é a representação de um mundo que existe independentemente, mas, antes, a "produção" de um mundo mediante o processo do viver. É importante salientar que a diferença entre o enfoque enativo e qualquer forma de construtivismo ou neokantianismo biológico está na ênfase na codeterminação. A abordagem atuacionista de Varela ou enação (e sua noção de mente incorporada) indica um caminho paradigmático nas ciências cognitivas.

\section{Aprendizagem móvel e ubíqua ${ }^{6}$}

Saccol, Schlemmer e Barbosa (2011) definem aprendizagem móvel e ubíqua. Para os autores, mobile learning ${ }^{7}$ se refere a processos de aprendizagem que ocorrem com o uso de dispositivos móveis, conectados a redes de comunicação sem fio, cuja característica fundamental é a mobilidade dos aprendizes, que podem estar distantes uns dos outros e também de espaços formais de educação. Essa mobilidade, além de física e temporal, é também tecnológica, conceitual e sociointeracional.

Ubiquitous learning (aprendizagem ubíqua) se refere a processos de aprendizagem que podem ocorrer com o uso de dispositivos móveis, conectados a redes de comunicação sem fio, sensores e mecanismos de geolocalização capazes de colaborar para integrar os aprendizes a contextos de aprendizagem e ao seu entorno, permitindo formar redes presenciais e digitais virtuais entre pessoas, objetos, situações ou eventos, de forma a possibilitar uma aprendizagem contínua e contextualizada. Nessa perspectiva, as interfaces que propiciam a interação humano-computador tendem a desaparecer, pois a computação estará "embutida", integrada em todos os locais e em diferentes objetos, ${ }^{8}$ tornando-se

6 Vinculado a esse contexto está a pesquisa "Aprendizagem com Mobilidade no contexto organizacional" (2006-2009), financiada pelo CNPq, bem como experimentos desenvolvido com estudantes do Programa de Aprendizagem Teorias de Aprendizagem, durante o primeiro semestre de 2012, no contexto de BYOD.

7 Aprendizagem móvel ou com mobilidade.

8 Por meio de redes de comunicação que permitem o tráfego de dados entre diferentes dispositivos e redes espalhadas por prédios, ruas, carros, enfim, em toda a parte. 
praticamente invisível. Para além da mobilidade, o conceito de ubiquitous learning indica que as tecnologias digitais potencializam a aprendizagem situada, disponibilizando ao sujeito informações "sensíveis" ao seu perfil, necessidades, ambiente e demais elementos que compõe seu contexto de aprendizagem em qualquer lugar e a qualquer momento. A essa possibilidade podem estar vinculadas tecnologias de localização, ${ }^{9}$ tecnologias de identificação, ${ }^{10}$ sensores, dentre outras.

A possibilidade do digital estar "embutido" em objetos e lugares torna possível também a "realidade misturada" e a "realidade aumentada", as quais combinam uma cena presencial física, vista por um sujeito, com uma cena digital virtual, sendo que no caso da realidade aumentada, o digital acrescenta informação à cena presencial física, ampliando-a, ou seja, "aumenta a cena", potencializando o conhecimento a respeito de objetos, lugares ou eventos.

\section{O lugar da Gamificação na relação jogos e educação}

O termo gamificação (gamification) começou a ser utilizado pela indústria de jogos em 2008 e se popularizou a partir de 2010. Desde então, vem sendo amplamente utilizado em diversos contextos, entre eles a educação. Gamification pode ser compreendido como o uso de elementos de design de jogos em contextos não jogo. Para Ziechermann e Linder (2010), gamificação é o processo de usar mecânica de games, estilo de games e o pensamento de games, em contexto não game, como meio para resolver problemas e engajar pessoas. A gamificação se ocupa, então, de analisar os elementos presentes no design de jogo, que fazem-no ser divertido, e adaptar esses elementos a situações que normalmente não são consideradas jogos. De acordo com McGonigal (2011), a Gamificação é

9 GPS, sistemas de navegação, sistemas de localização de pessoas, jogos móveis que se utilizam de geolocalização.

10 RFID (Radio-Frequency IDentification) - método de identificação automática através de sinais de rádio, recuperando e armazenando dados remotamente através de dispositivos denominados etiquetas RFID; e QRCode (Quick Response) - código de barras bidimensional que pode ser escaneado utilizando telefones celulares com câmera. Esse código pode se referir a um texto (interativo), um endereço URL, um número de telefone, uma localização georreferenciada, um e-mail, um contato ou um SMS. um fenômeno recente que propõe o uso de jogos digitais para resolver problemas sociais e envolver o público. A gamificação se propõe a criar uma camada de jogo numa aplicação ou produto, no lugar de ser, na origem, um jogo.

A gamificação pode ser pensada a partir de pelo menos duas perspectivas: enquanto persuasão, estimulando a competição, tendo um sistema de pontuação, de recompensa, de premiação etc., o que do ponto de vista da educação reforça uma perspectiva epistemológica empirista; e enquanto construção colaborativa e cooperativa, instigada por desafios, missões, descobertas, empoderamento em grupo, o que do ponto de vista da educação nos leva à perspectiva epistemológica interacionista-construtivista-sistêmica (inspirados, por exemplo, por elementos presentes nos Massively Multiplayer Online Role Play Games - MMORPG).

No que se refere aos jogos, McGonigal (2011) afirma que as pessoas preferem jogos de cooperação. Ela comenta que se olharmos para o que acontece nos jogos, veremos que a maioria das pessoas não quer competir, mas, sim, trabalhar com os seus amigos para atingir um objetivo comum. De acordo com a autora, se os jogadores estão dispostos a realizar desafios que envolvem obstáculos muitas vezes desnecessários, os jogos têm a capacidade de mobilizar, então podem ser utilizados como tecnologia de transformação social.

No que se refere à relação jogos e educação, é possível pensar:

a) o uso de jogos na educação, o qual pode envolver as seguintes perspectivas:

- jogos educacionais (jogos criados com objetivos educacionais para trabalhar conteúdos específicos com os estudantes);

- jogos cujo objetivo da criação não é educacional, mas podem ser explorados em diferentes contextos de aprendizagem, tal como os jogos comerciais: Age of Empire, Civilization, entre outros, para estudar história; Globetrotter XL e Carmen Sandiego para geografia; Spore para biologia; Guitar Hero para música; Brain Age para matemática, entre tantos outros; 
- $\quad$ softwares que permitem que o sujeito crie seus próprios jogos, tais como o Scratch (linguagem de programação desenvolvida pelo Grupo de Lifelong Kindergarten no Media Lab do MIT); o ARIS Games - plataforma open-source para a criação de jogos para celular, usando o GPS e QRCodes, Gamemaker e Construct 2, e o Microsoft KODU, linguagem de programação que permite criar jogos para a plataforma de jogos Xbox;

b) a construção de narrativas interativas (essa perspectiva envolve a criação de narrativas interativas a partir das novas mídias, ${ }^{11}$ possibilitando ao sujeito criar a sua própria narrativa ao mesmo tempo em que participa dela, provocando, assim, um nível maior de envolvimento, de imersão). Nessa perspectiva, uma história pode se desdobrar em diversas outras que podem estar acontecendo em tempos e espaços paralelos;

c) a gamificação na educação (quando se utiliza mecânica, estilo e pensamento de jogos, em contextos não jogos, como meio para a resolução de problemas e engajamento dos sujeitos). Um exemplo de uso da gamificação na educação pode ser encontrado quando se faz uso de elementos de design de jogos para resignificar e desenhar numa outra perspectiva, a da gamificação, o currículo, as práticas e os processos de mediação pedagógica.

Assim, tanto a presença dos jogos (integração de jogos nas experiências educacionais), quanto a construção de narrativas interativas utilizando diferentes mídias, bem como a gamificação, vêm crescendo em importância na educação, na medida em que as pesquisas evidenciam a sua contribuição para: 1) um maior envolvimento efetivo dos sujeitos nos processos de ensino e de aprendizagem, favorecendo o desenvolvimento da autonomia, da autoria, da colaboração, da cooperação, bem como instigando a solução de problemas e o pensamento crítico; 2) ampliar as possibilidades da construção de sentidos

11 De acordo com Ferreira (2006), esse termo se refere à soma de tecnologias e métodos de comunicação, como forma de diferenciação dos clássicos canais de comunicação como TV, rádio, imprensa, cinema, dentre outros.
- significação de conceitos, de forma divertida; 3) o desenvolvimento cognitivo e sociocognitivo, por meio da vivência de diferentes experiências.

\section{Dos Espaços de Convivência Digitais Virtuais (ECODI) aos Espaços de Convivência Híbridos e Multimodais}

A tecnologia-conceito Espaço de Convivência Digital Virtual (ECODI), utilizada por Schlemmer (2006) no contexto do Grupo de Pesquisa em Educação Digital (GPe-dU UNISINOS/CNPq), é resultado de uma construção técnica e teórica vinculada às pesquisas desenvolvidas desde 1998 sobre o uso das TD em processos de ensino e aprendizagem, numa abordagem interacionista-construtivista-sistêmica. Um ECODI, de acordo com Schlemmer et al (2006) e Schlemmer (2008, 2009), compreende:

- diferentes TD integradas: AVA, tecnologias da Web 2.0, Web 3D, agentes comunicativos (agentes não humanos criados e programados para a interação), dentre outros, que favoreçam diferentes formas de comunicação (textual, oral, gráfica e gestual);

- fluxo de comunicação e interação entre os sujeitos presentes nesse espaço;

- fluxo de interação entre os sujeitos e o meio, ou seja, o próprio espaço tecnológico.

Um ECODI pressupõe, fundamentalmente, um tipo de interação que possibilita aos "e-habitantes" (considerando sua ontogenia) desse espaço configurá-lo de forma colaborativa e cooperativa, por meio do seu viver e do conviver.

Entretanto, resultados das últimas pesquisas (SCHLEMMER, 2010a, 2010b; SCHLEMMER; SILVA; SACCOL, 2008) evidenciaram uma referência significativa dos participantes sobre a importância e a contribuição que diferentes TD integradas (principalmente da Web 2.0 e Web 3D) utilizadas também a partir de celulares e tablets, na vinculação com espaços analógicos, podem trazer para a aprendizagem, referindo dessa forma a coexistência e a necessidade de imbricamento dos mundos presenciais físicos e digitais virtuais. No que se refere especificamente à pesquisa Anatomia no metaverso Second Life: uma proposta em i-Learning 
(SCHLEMMER, 2010b), foi possível identificar que a imersão por avatar em ambientes $3 \mathrm{D}$, quando associada a desafios/problematizações/pistas, ${ }^{12}$ propicia um maior envolvimento dos estudantes com o objeto em estudo, o que foi manifestado em relatos como: "parece um jogo, a gente aprende jogando, é divertido, nem vimos o tempo passar". ${ }^{13}$ Outro resultado da pesquisa apontou a importância salientada pelos estudantes de ter o ambiente em $3 \mathrm{D}$, associado aos livros, laboratórios de anatomia e, principalmente, à presença do professor, o que indica que, na visão deles, a tecnologia digital não substituí as tecnologias tradicionais, mas, sim, ambas se complementam e podem coexistir no universo educacional. Esses resultados indicam que experiências em Immersive Learning, vinculadas à gamificação, podem enriquecer contextos de aprendizagem, compondo ambientes híbridos, na perspectiva da multimodalidade.

Esses indícios nos levaram a pensar na possibilidade de configuração de Espaços de Convivência Híbridos e Multimodais (ECHM), o que pressupõe o imbricamento de ECODI com outros espaços analógicos, bem como a perspectiva da multimodalidade, integrando mobile Learning, ubiquitous Learning, immersive Learning, gamification Learning e modalidade presencial física. A hipótese é a de que nesse processo de configuração de ECHM seja possível encontrar elementos que nos permitam construir novas metodologias e práticas pedagógicas no contexto do ensino superior.

\section{Metodologia}

O contexto metodológico utilizado neste artigo é um recorte da metodologia da pesquisa na qual está inserido. Portanto, trata-se de uma pesquisa de natureza exploratória e abordagem qualitativa que utiliza, como método para o seu desenvolvimento, a Design Research e a cartografia.

O método cartográfico proposto por Deleuze e Guatarri (1995), e que tem sido explicitado e investigado no Brasil por Kastrup (2008) e Passos, Kastrup e Escóssia (2012), entre outros, surgiu como um caminho possível para essa pesquisa, justamente por entender que as dimensões da sub-

12 Elementos presentes na mecânica dos jogos.

13 Fala de um dos sujeitos da pesquisa. jetividade humana apontam para a necessidade de metodologias que possam acompanhar e registrar os percursos dos sujeitos e coletividades num determinado contexto.

A Design Research, trazida para o campo da educação inicialmente por Brown (1992) e Collins (1992), a partir do conceito de design experiments, consiste numa metodologia para resolver problemas complexos em contextos reais, a partir da colaboração entre diferentes atores, a fim de testar e aperfeiçoar ambientes de aprendizagem inovadores. De acordo com Brown (1992), esse método é adequado para analisar sistemas complexos e interativos envolvendo múltiplos elementos, de naturezas distintas, denominado por ela "ecologias de aprendizagem". ${ }^{14}$ Segundo Edelson (2002), essa metodologia pode gerar três tipos de teorias: Domínio das Teorias - descrevem as situações de aprendizagem e suas interações; Quadro de Design - fornece orientações para um projeto; Metodologias do Design - diretrizes para a implementação do projeto, podendo servir de base para novos projetos.

Como instrumentos, a pesquisa utiliza observação, registros fotográficos digitais, registros em filmadoras digitais, registros orais em áudio digital e registros escritos, em diferentes espaços de interação no contexto do hibridismo e da multimodalidade. Para as transcrições e análises dos vídeos é utilizado o software Transana. ${ }^{15}$

Como metodologia para a análise dos dados faz uso da análise textual discursiva (GALIAZZI; MORAES, 2011), sendo os dados organizados em subsistemas de informações, categorizados e armazenados, utilizando o software NVivo. ${ }^{16} \mathrm{~A}$ interpretação dos dados produzidos está sendo realizada considerando o referencial teórico que fundamenta a pesquisa.

$14 \mathrm{O}$ uso da metáfora relativa à ecologia enfatiza a natureza interativa dos contextos investigados e a importância de analisar seus diversos elementos em conjunto e não separadamente.

15 Desenvolvido pelo Madison Center for Education Research, da Universidade de Wiscosin, EUA, permite a transcrição dos dados em áudio e vídeo e a criação de categorias de análise em banco de dados, possibilitando a seleção de recortes do material digital para consolidação das análises.

16 Esse software permite a categorização de múltiplos dados de pesquisa de diferentes formatos e fontes digitalizadas, como URL, imagens, textos, áudio, vídeo, tabelas, gráficos, entre outros. Trata-se de uma ferramenta de análise importante na geração de nexos e significância no inter-relacionamento de categorias de análise com base em diferentes fontes de dados. 
Os sujeitos-participantes dessa pesquisa são professores e estudantes da Atividade Acadêmica Cognição em Jogos Digitais do curso superior de Tecnologia em Jogos Digitais, da UNISINOS.

A partir dessa contextualização e fundamentação teórico-metodológica, apresento o design da experiência "Construção de espaços de convivência híbridos e multimodais na perspectiva da Gamificação" em processo de construção na ação-reflexão-ação docente, inspirada no método cartográfico de pesquisa-intervenção, enquanto possibilidade para a ação docente e aprendizagem dos envolvidos no processo (professores e estudantes).

\section{Construção de espaços de convivência híbridos e multimodais na perspectiva da Gamificação: $O$ design da experiência em construção na ação-reflexão-ação docente}

Na atualidade, há uma multiplicidade de teorias de design, entre elas: design instrucional, design educacional, design da interação, design afetivo, codesign, design thinking, entre outros.

Design, no contexto deste artigo, é entendido a partir de Schön (2000), que propõe a ideia de uma prática reflexiva, intuitiva, onde os objetivos não são fixos e o problema não está completamente definido. Nesse contexto, faz-se necessário pensar o que se está fazendo enquanto se está fazendo, o que configura um tipo de reflexão na ação, sendo que esta ocorre em situações únicas, incertas, complexas, que precisam ser resolvidas, em que o problema não é dado e existe um problema em encontrar o problema.

A teoria de Schön (2000) apresenta uma visão do processo de design que possui uma prática reflexiva, intuitiva, fluida e com os objetivos em aberto. Entretanto, o que acontece no processo de “desenhar-e-pensar”? Para Maia (2011, p. 298),

Existem aspectos inequívocos sobre a actividade de design que determinam a sua configuração enquanto dimensão de pensamento com particularidades exclusivas. A natureza dos problemas de design determinam aprender sobre o problema numa abordagem por tentativa e erro, onde a experiência acumulada é o factor mais estabilizador e seguro do processo. Não existe apenas um único modo de conceber, existe sim uma configuração possível para um modo de pensar que reflecte sobre si próprio ao longo do processo de design e que assenta as suas opções naquilo que cada problema apresenta de incerteza e desconhecido, arriscando novas possibilidades para a configuração das soluções. É uma dialéctica que ocorre entre o designer e o problema e entre o problema e a solução.

Dessa forma, a compreensão de design nessa pesquisa parte da perspectiva apresentada por Schön (2000) e busca inspiração no conceito de Design Thinking, enquanto uma proposta para "desenhar o pensamento", tendo como foco a maneira de pensar dos envolvidos no processo. A proposta é centrar o projeto (aqui compreendido como a Atividade Acadêmica Cognição em Jogos Digitais) no pensamento dos atores participantes dessa atividade. Nesse contexto, é possível compreender que estamos falando de design cognitivo. No caso específico deste artigo, a análise será do ponto de vista dos docentes em processo de construção de sua ação e, portanto, o foco está nas pessoas, suas experiências e de que forma elas lidam com os problemas que surgem ao longo do processo. Assim, a partir do design inicial da atividade, os professores elaboraram um planejamento inicial, contendo somente o detalhamento do primeiro encontro. ${ }^{17}$

No primeiro encontro da atividade foi iniciado um diálogo, a fim de melhor conhecer os sujeitos da aprendizagem, o que esperavam da atividade e como gostariam que ela se desenvolvesse. ${ }^{18}$ Após esse momento, os professores apresentaram a proposta inicial da atividade, bem como a pesquisa a ela vinculada, as quais foram colocadas em discussão. Ficou acordado que, para além dos encontros presenciais físicos semanais, aos quais todos poderiam trazer seus dispositivos móveis (BYOD), seria criada uma comunidade no Moodle e um grupo no Facebook. Na sequência, deu-se início ao desencadeamento dos projetos de aprendizagem, no caso, jogos ou situações gamificadas, os quais poderiam ser de natureza analógica, digital ou, ainda, híbrida. Os grupos foram formados a partir da afinidade de interesses no tipo de jogo ou situação gamificada a ser desenvolvida e temática, sendo definidas as

17 É importante considerar que quando o planejamento inicial de uma atividade acadêmica é desenvolvido, não se tem conhecimento de quem serão os sujeitos da aprendizagem que irão se matricular.

18 Também foi disponibilizado no Google formulário, um questionário para conhecer o perfil dos estudantes. 
atribuições de cada integrante no grupo: gerente do projeto e demais funções necessárias à opção realizada. Ficou definido que o desenvolvimento dos projetos teriam como sujeitos-teste os próprios estudantes da atividade acadêmica, além de outros públicos definidos pelos grupos. Acordou-se ainda que a avaliação se daria no acompanhamento do processo de aprendizagem de cada estudante, ao percorrer as diferentes fases, as quais possibilitam conquistar poderes (conhecimentos construídos). A possibilidade de conquistar mais poderes ocorre na medida em que: ampliam os observáveis na ação de jogar (em função da atribuição de sentidos à teoria em estudo); buscam e indicam referências relevantes (textos, áudios, vídeos, jogos, apps etc.); evidenciam condutas de autonomia e autoria nos processos de interação e construção do projeto; criam redes de interações no grupo e entre os grupos; propõem questões, socializam reflexões e realizam críticas; compartilham os conhecimentos, colaboraram e cooperam entre si; identificam o interesse e envolvimento dos sujeitos-teste com o jogo ou situação gamificada criada. Ao final do encontro, os estudantes preencheram o Termo de Consentimento Livre e Esclarecido para participar da pesquisa.

O processo e os resultados desse primeiro encontro foram colocados em relação com o design inicial da atividade acadêmica. Nesse momento, percebeu-se a oportunidade de trabalhar com achievements, ${ }^{19}$ que poderiam ser liberados em função do próprio desenvolvimento dos estudantes na atividade gamificada. Assim, foram pensados os seguintes achievements: observador, ${ }^{20}$ explorador, ${ }^{21}$ ator; ${ }^{22}$ tecelão; ${ }^{23}$ cartógrafo; ${ }^{24}$ problematizador; ${ }^{25}$

19 Na linguagem dos jogos, achievements (conquistas) são objetivos que um sujeito pode alcançar durante o jogo. Eles podem ser explícitos e/ou secretos, ou seja, que o sujeito descobre durante o processo de jogar.

20 Observar a si, crianças, adolescentes, jovens, adultos e até mesmo os colegas durante a ação de jogar, buscando compreender como essa ação ocorre, quais semelhanças e diferenças etc., ou seja, nosso objetivo era saber o que era observável e significativo para os estudantes no que se referia à ação de jogar.

21 Desvendando as pistas, jogos + teorias+educação - busca por referências - autonomia.

22 Construção do concept, do jogo e do modelo de avaliação de jogos - autoria criativa.

23 Encontrando conexões - observador+explorador+ator, criação de redes.

24 Mapeando o caminho - análise do processo, autoavaliação-reflexão.

25 Instigador, que provoca questões, reflexões, críticas. colaborador; ${ }^{26}$ cooperador. ${ }^{27}$

Dessa forma, os demais encontros foram acontecendo semanalmente, acompanhados de uma avaliação do processo vivenciado e precedidos de um encontro entre os professores para planejamento da semana seguinte.

No segundo encontro, deu-se início ao processo de gamificação - FASE I - O EXPLORADOR CAÇA À TEORIA - foram criadas algumas pistas, utilizando QRCodes, as quais foram espalhadas pelo prédio da biblioteca, em quatro locais distintos, incluindo área externa. As pistas continham informações sobre as seguintes teorias: Biologia do Conhecer, de Humberto Maturana e Francisco Varela; Epistemologia Genética, de Jean Piaget; Conectivismo, de George Siemens; Teoria Ator-Rede de Bruno Latour (Figura 1). Cada grupo de projeto se direcionou a um local geográfico específico, no qual havia um conjunto de pistas sobre uma determinada teoria. Assim, cada grupo ficou conhecendo qual a teoria que iria subsidiar o desenvolvimento do seu projeto (Figura 2). No entanto, um grupo não poderia contar para o outro qual a sua teoria, pois a identificação de elementos das diferentes teorias, presentes no desenvolvimento dos projetos, também fazia parte da gamificação

Figura 1 - Pistas sobre as teorias

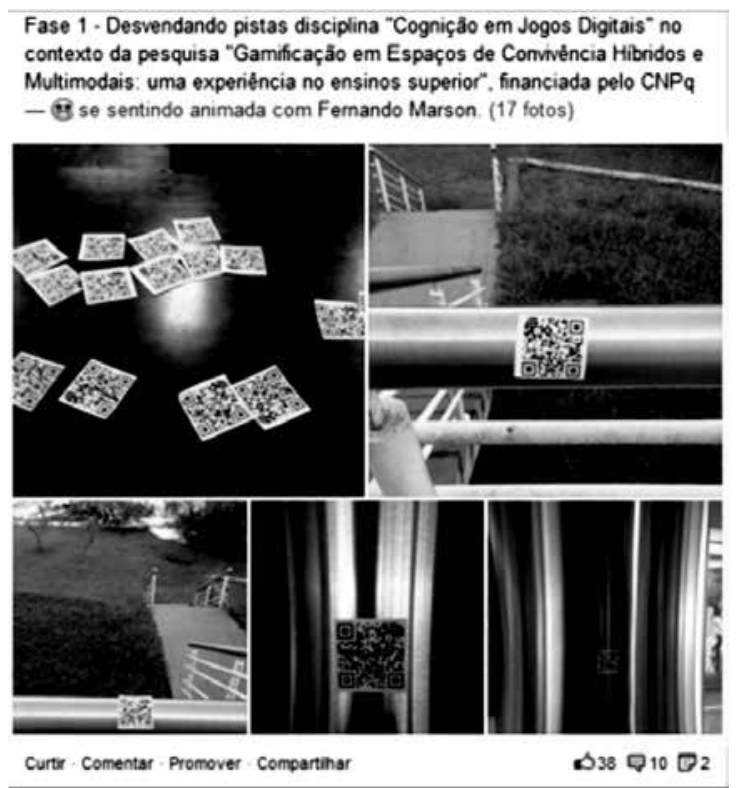

Fonte: Acervo particular da autora.

26 Que contribui com os demais com alguma referência.

27 Que cria junto com os demais. 
Figura 2 - FASE I - O EXPLORADOR

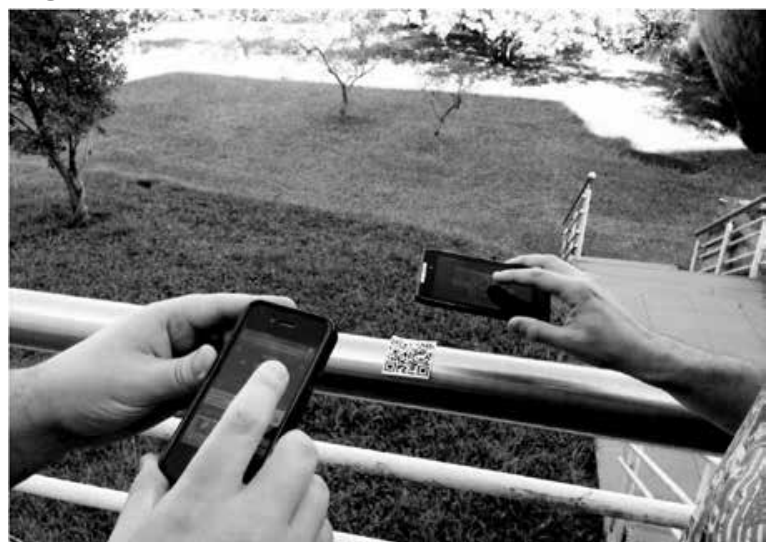

Fonte: Acervo particular da autora.

\section{Figura 3 - FASE II - O OBSERVADOR}

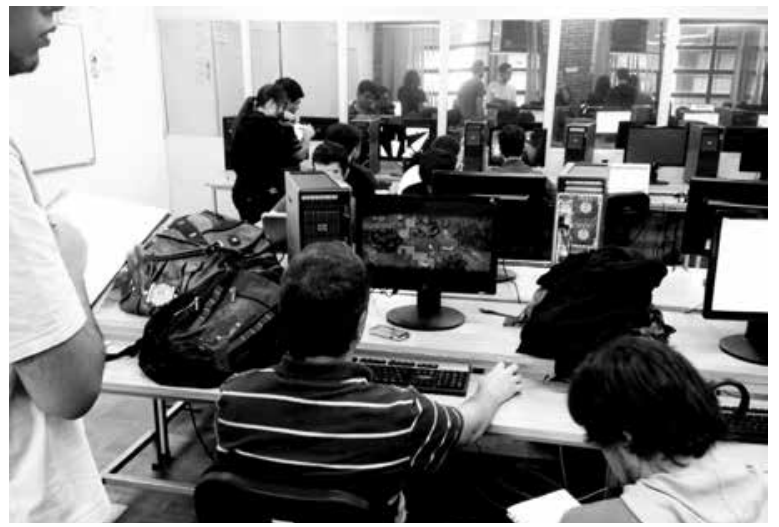

Fonte: Acervo particular da autora.

No terceiro encontro - FASE II - O OBSERVADOR - BUSCANDO PISTAS AO JOGAR, foram disponibilizados nove jogos para que os estudantes pudessem jogá-los a fim de buscar pistas sobre o seu próprio processo de jogar, e, após, buscar pistas sobre o processo de jogar dos colegas. O objetivo era conhecer quais eram os observáveis identificados por eles. Esses observáveis foram registrados num diário de viagem para serem posteriormente retomados à luz das teorias estudadas (Figura 3). O processo se desenvolveu em dois momentos:

- Primeiro momento: 1) cada estudante escolheu três jogos para jogar; 2) ação de jogar; 3) análise - busca por pistas - reflexão sobre a ação de jogar - registro dos observáveis (o que percebe do jogo em si? o que percebe da ação de jogar? o que percebe de si ao jogar?);
- Segundo momento: 1) cada estudante escolheu três jogos para observar três colegas jogando; 2) observação; 3) análise - buscas por pistas - reflexão sobre a ação de jogar do colega - registro dos observáveis (o que percebe do jogo em si? o que percebe da ação do outro sobre o jogo - jogar? o que percebe de si enquanto observador?).

No quarto encontro - FASE III - O EXPLORADOR - DESVENDANDO MISTÉRIOS DA ÁREA DE GAMES NA RELAÇÃO COMA EDUCAÇÃO, teve início a fase das Pistas Vivas, com a participação, por meio de webconferência, de um professor convidado. O processo se desenvolveu em dois momentos:

- Primeiro momento: foram criadas pistas utilizando QRCodes (Figura 4), nas quais foram disponibilizadas: uma foto, um vídeo e um texto sobre a I Pista Viva. O objetivo consistia em descobrir a identidade da Pista Viva, bem como reunir o máximo de informações sobre as atividades que desenvolve, a fim de que tivessem elementos para realizar questionamentos à Pista Viva no momento da webconferência.

Figura 4 - Primeiro momento da FASE III

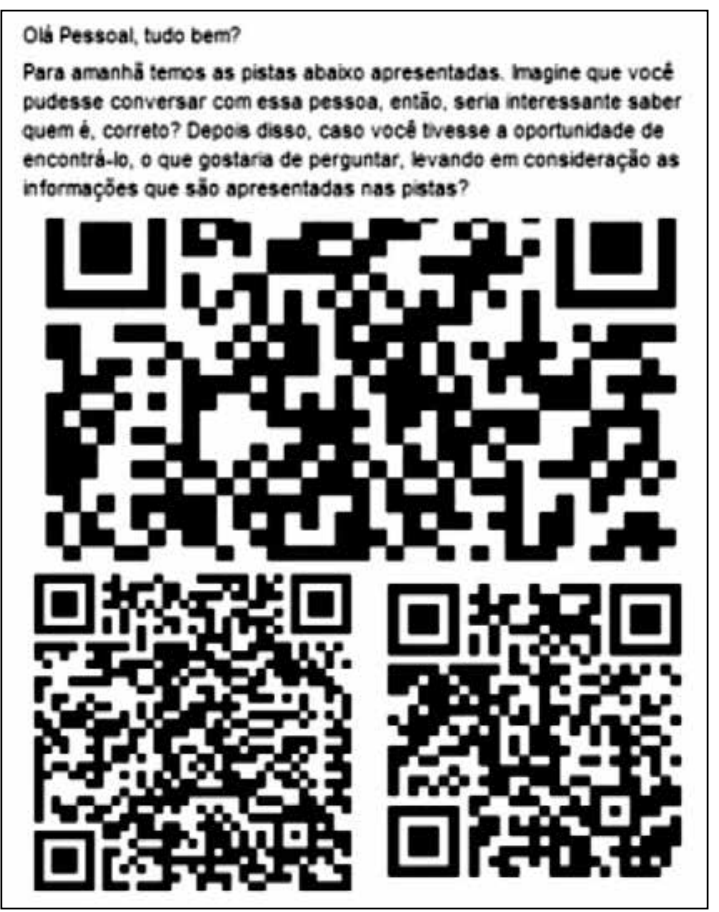

Fonte: Acervo particular da autora. 
- Segundo momento: realização da webconferência com a I Pista Viva (Figura 5).

Figura 5 - Segundo momento da FASE III O EXPLORADOR

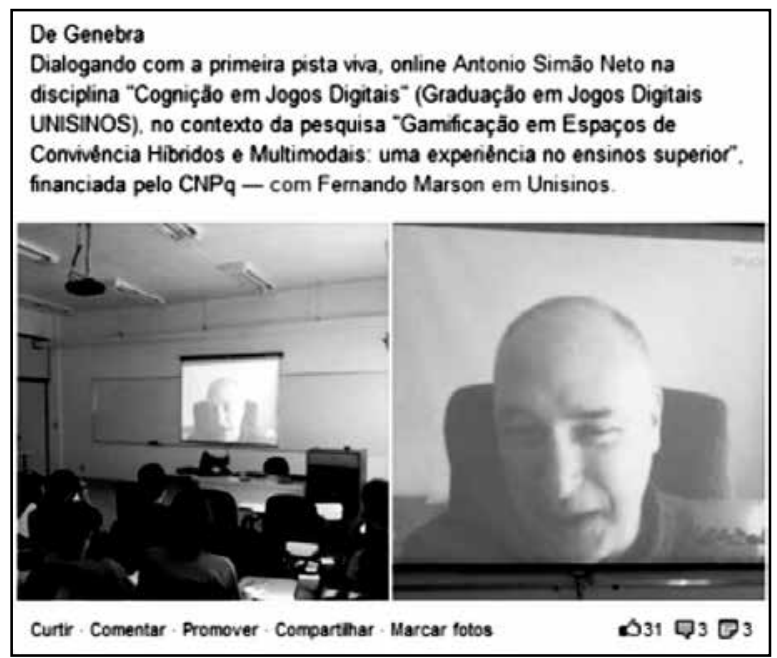

Fonte: Acervo particular da autora.

No quinto encontro - FASE IV - O TECELÃO - TECENDO AS OBSERVAÇÕES, encontrando conexões nas observações dos jogos. $\mathrm{O}$ processo se desenvolveu em quatro momentos (Figura 6):

- Primeiro momento: grupo por jogo - os estudantes reuniram-se em grupos, de acordo com o jogo observado, a fim de identificar o que foi recorrente e o que foi divergente, buscando classificar os observáveis;

- Segundo momento: discussão no grande grupo, por jogo, a fim de iniciar a criação de um "modelo" para avaliar jogos, fundamentado na classificação dos observáveis;

- Terceiro momento: grupo por projetos (concept+teoria) - os estudantes, por grupo de projeto, se reuniram para identificar o que das observações realizadas nos jogos poderia ser vinculado com a teoria em estudo;

- Quarto momento: discussão nos grupos por projetos - vinculado os observáveis à teoria em estudo.
Figura 6 - Diferentes momentos da FASE IV O TECELÃO

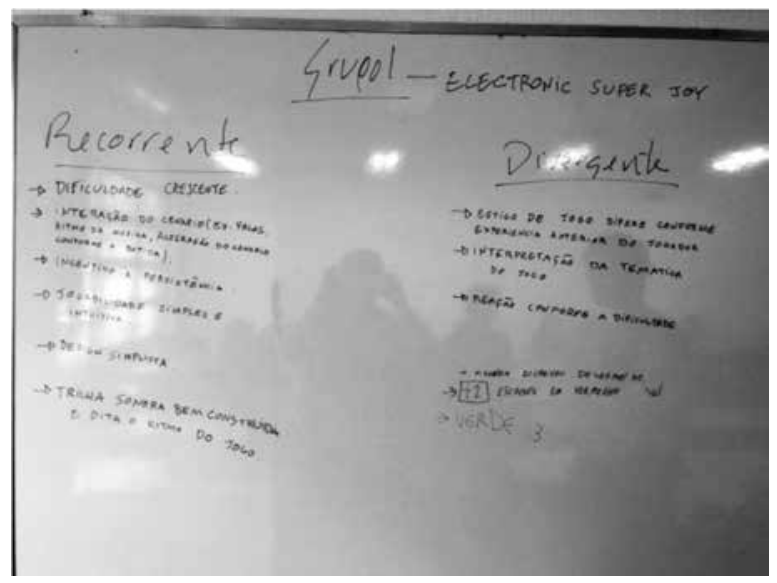

Mut:as điscussర̄es e significaç̋̃es interessantes a partr das observaç̋̄es "em jogo" na Atividade Acadèmica "Cognição em Jogos Digitais" (Graduação em Jogos Digțais UNISNOS), no contexto da pesquisa 'Gamificação em Espaços de Convivència Hibridos e Multimodais: uma experiencia no ensinos superior", financiada pelo CNPQ.

ETAPA V - Processo de construçăo de instrumentos startada - \& se sentindo animada com Fernando Marson e Unisinos.
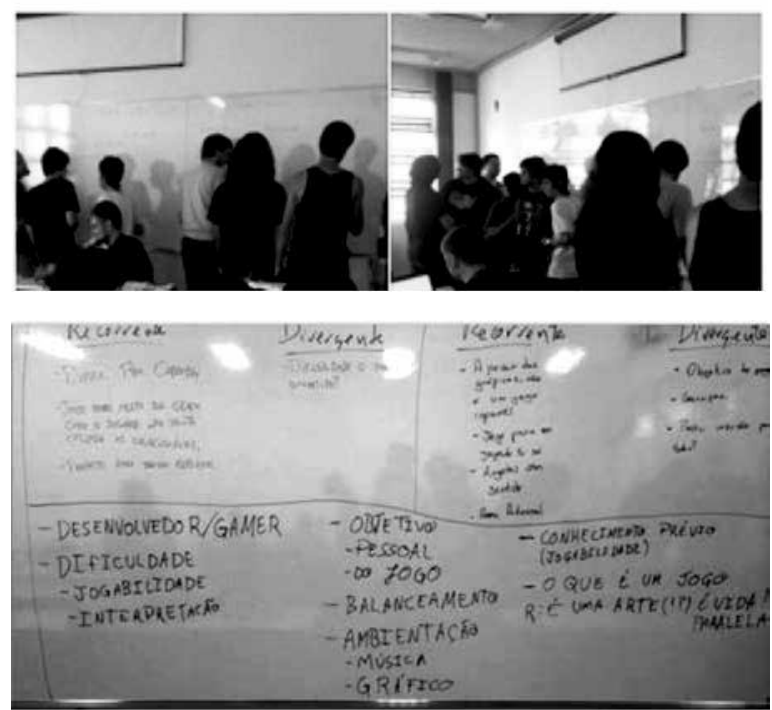

Fonte: Acervo particular da autora.

No sexto encontro - FASE V - O ATOR CONSTRUINDO OS CONCEPTS, construção dos concepts dos projetos em grupo. O processo se desenvolveu em dois momentos:

- Primeiro momento: trabalho nos grupos por projetos (Figura 7);

- Segundo momento: filmagem de cada grupo apresentando o concept de seu respectivo projeto. 
Figura 7 - Primeiro momento da FASE V - O ATOR

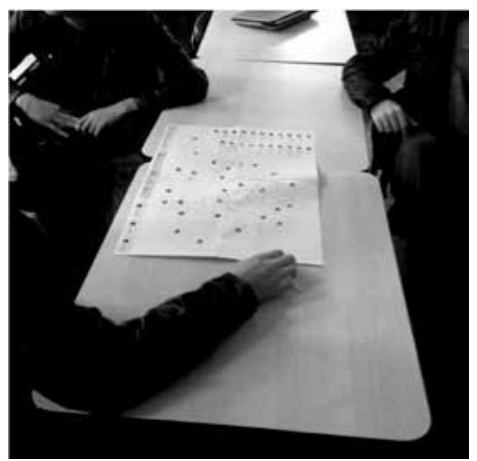

Fonte: Acervo particular da autora.

No sétimo e oitavo encontros - FASE VI - O CARTÓGRAFO - MAPEANDO O CAMINHO, cada grupo realizou o checkpoint do desenvolvimento dos projetos, apresentando-o para todo o grupo. O processo de se desenvolveu em dois momentos (Figura 8):

- Primeiro momento - apresentação dos grupos de projeto;

- Segundo momento - discussão com o grupo e questionamentos relacionados às apresentações do desenvolvimento dos projetos, na relação com o "modelo" para avaliar jogos, em processo de criação.

Figura 8 - Diferentes momentos da FASE VI - O CARTÓGRAFO

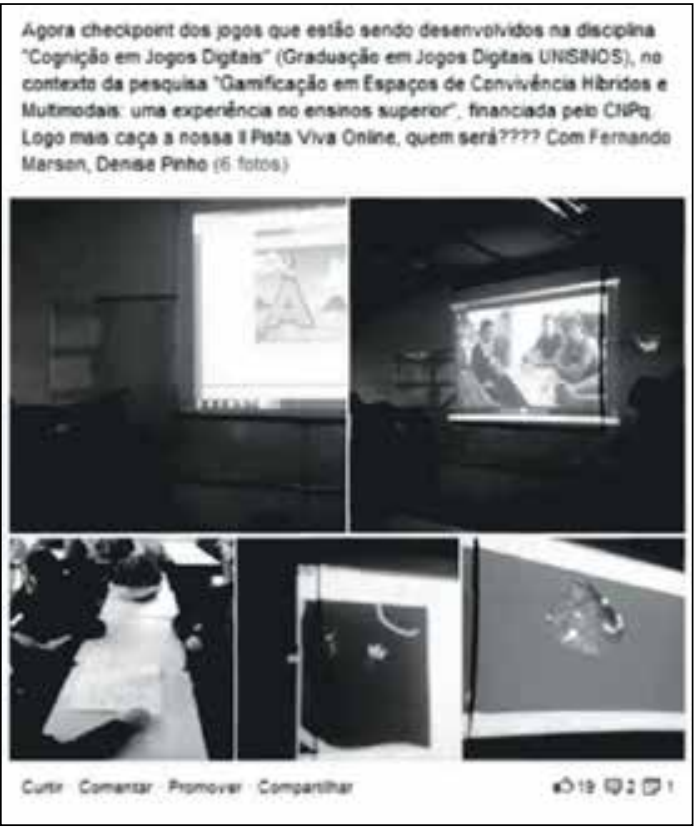

Fonte: Acervo particular da autora.
No oitavo e nono encontro-FASE VII - O ATOR - CONSTRUINDO O MAPAE O JOGO, o processo se desenvolveu em três momentos (Figura 9):

- Primeiro momento - retomada da construção do "modelo" para avaliar jogos, a partir da discussão e dos questionamentos realizados;

- Segundo momento - trabalho no desenvolvimento dos projetos em grupo;

- Terceiro momento - autoavaliação e avaliação do desenvolvimento da Atividade Acadêmica até o momento, a fim de corrigir rumos, caso necessário.

Figura 9 - FASE VII - O ATOR

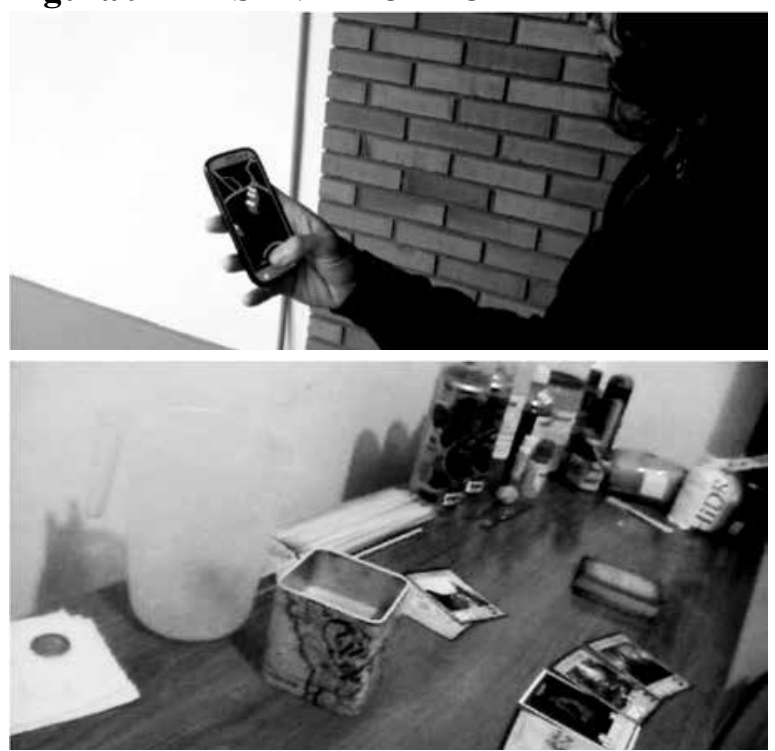

Fonte: Acervo particular da autora.

Décimo, décimo primeiro, décimo segundo e décimo terceiro encontros - FASE VIII - O EXPLORADOR - DESVENDANDO MISTÉRIOS DAS TEORIAS - Pistas Vivas com a participação, por meio de webconferência e também de forma presencial física, de professores convidados vinculados às diferentes teorias em estudo. Esses quatro encontros se desenvolveram nos seguintes momentos (Figuras 10, 11, 12 e 13):

- Primeiro momento - foram criadas, utilizando o Aurasma, ${ }^{28}$ as pistas (vídeos e fotos) geolocalizadas no campus, de acordo com

28 Aurasma é um aplicativo para dispositivos móveis que possibilita criar realidade misturada ou realidade aumentada, possibilitando, assim, acrescentar informações digitais em uma cena do mundo presencial físico, analógico, ampliando a "realidade". 
as diferentes áreas de formação dos teóricos criadores das teorias em estudo, bem como as pistas com informações (vídeos e fotos) sobre as Pistas Vivas, que discutiram com os estudantes sobre as teorias em estudo. É importante salientar que o nome da teoria permanecia em segredo para o grupo de estudantes, com exceção do grupo específico que estava estudando a teoria em questão, em razão de ter realizado pesquisas anteriores sobre ela;

- Segundo momento - os estudantes percorriam o campus para encontrar as pistas;

- Terceiro momento - realização da webconferência com a Pista Viva para discutir as teorias (no momento da webconferência, as pistas vivas iniciavam a conversa sem, no entanto, mencionar o nome da teoria em questão. Este só seria revelado ao final, caso os estudantes não identificassem a teoria que estava sendo apresentada e discutida.

Figura 10 - I Pista Teórica - Conectivismo e II Pista Viva - FASE VIII - O EXPLORADOR

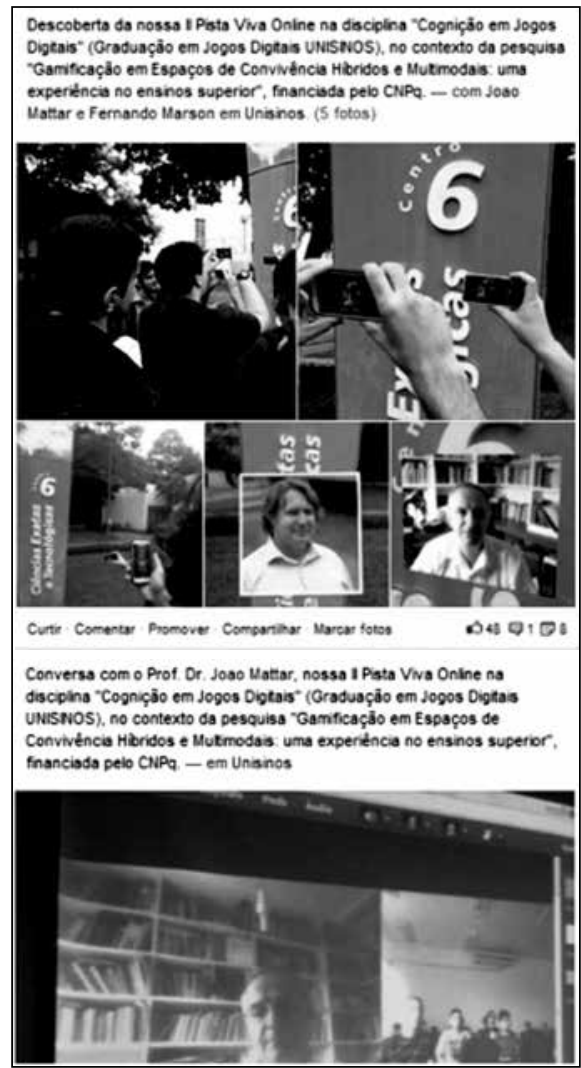

Fonte: Acervo particular da autora.
Figura 11 - II Pista Teórica - Biologia do Conhecer e III Pista Viva FASE VIII - O EXPLORADOR

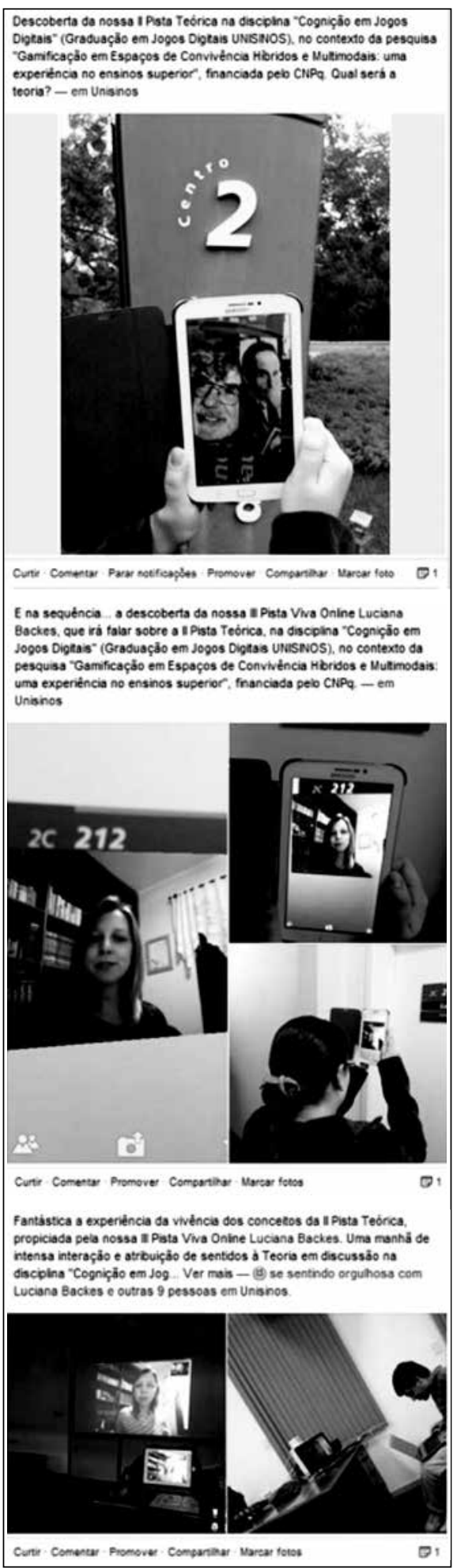

Fonte: Acervo particular da autora. 
Figura 12 - III Pista Teórica - Teoria Ator-Rede e IV Pista Viva (esta pista viva esteve de forma presencial física com os estudantes) - FASE VIII - O EXPLORADOR

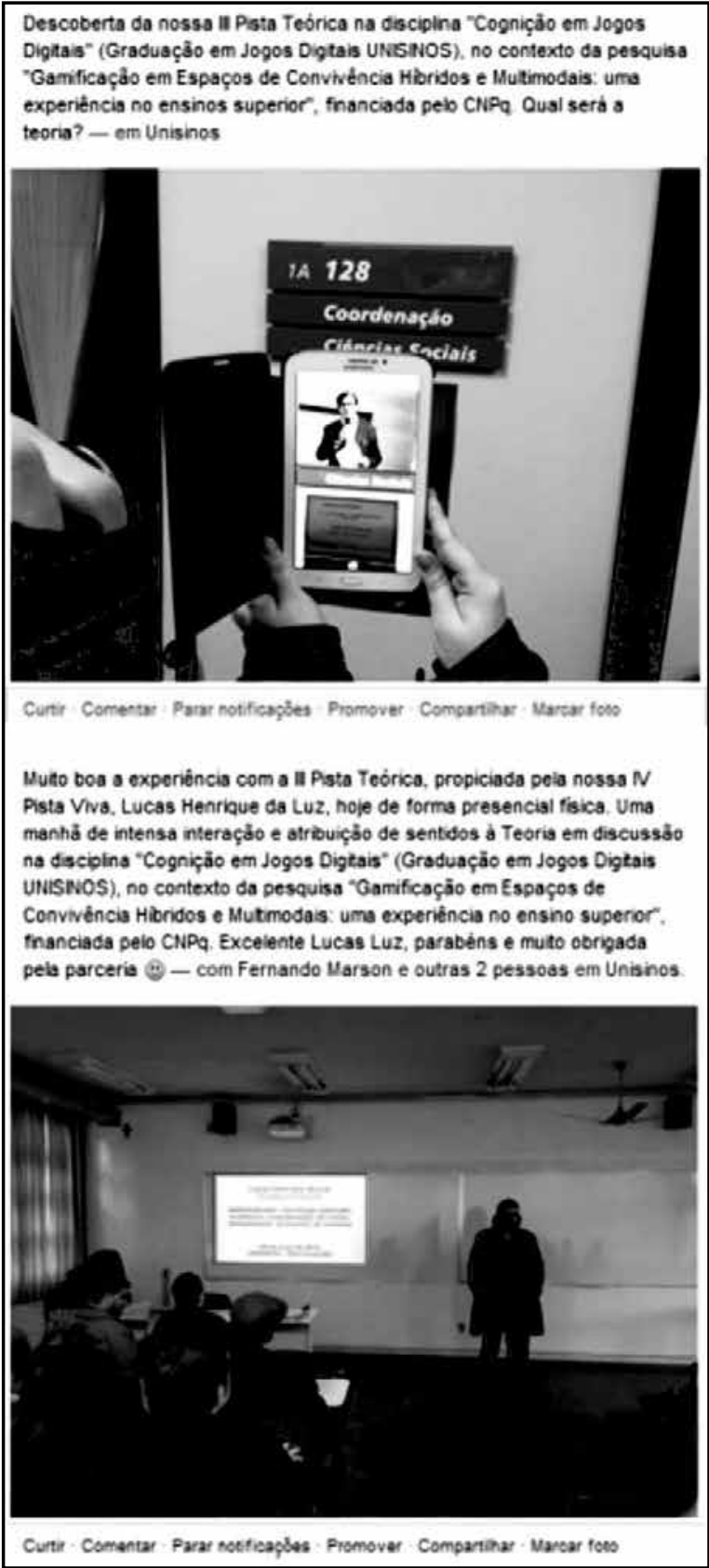

Fonte: Acervo particular da autora.
Figura 13 - IV Pista Teórica - Epistemologia Genética de Jean Piaget e V Pista Viva - FASE VIII - O EXPLORADOR

Descoberta da nossa $\mathrm{N}$ e útima Pista Teónica na disciplina "Cogniçảo en Jogos Digtais" (Graduaçüo em Jogos Digtais UNSWOS), no contexto da pesquisa "Gamificaçăo em Espaços de Convivència Hibridos e Mutimodais uma experiència no ensinos superior., financiada peb CNipa Qual será a teoria? - com Fernando Narson em Unisinos.

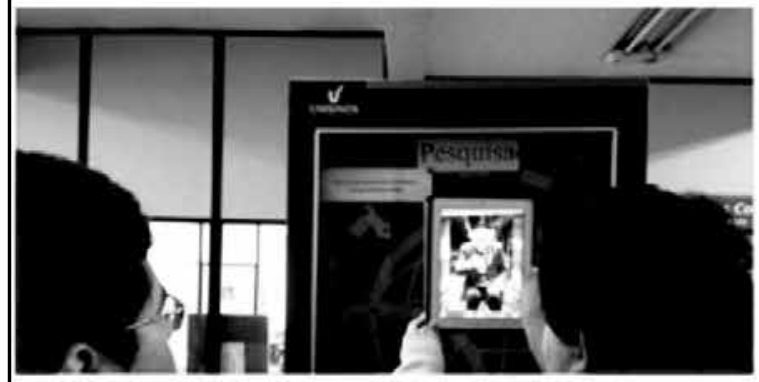

E na sequência... a descoberta da nossa V Pista Viva online Daniel Lopes e que irá falar sobre a IV Pista Teónca, na disciplina "Cognição em Jogos Digitais" (Graduação em Jogos Digitais UNISINOS). no contexto da pesquisa "Gamificaçäo em Espaços de Convivência Hibridos e

Multimodais: uma experiencia no ensinos superior", financiada pelo $\mathrm{CNPq}$ - com Fernando Marson em Unisinos.

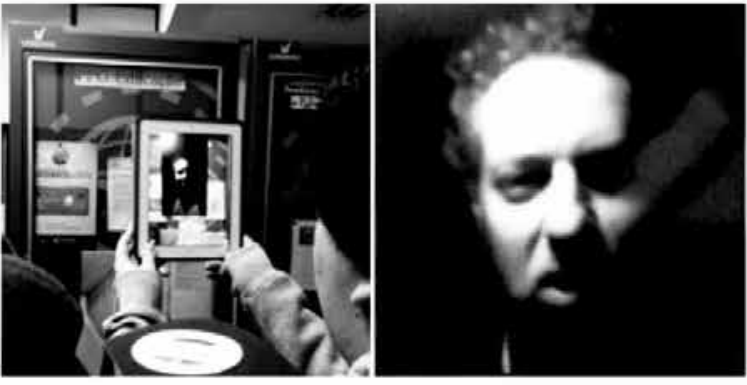

Curtir - Comentar - Promover - Comparthar-Marcar fotos

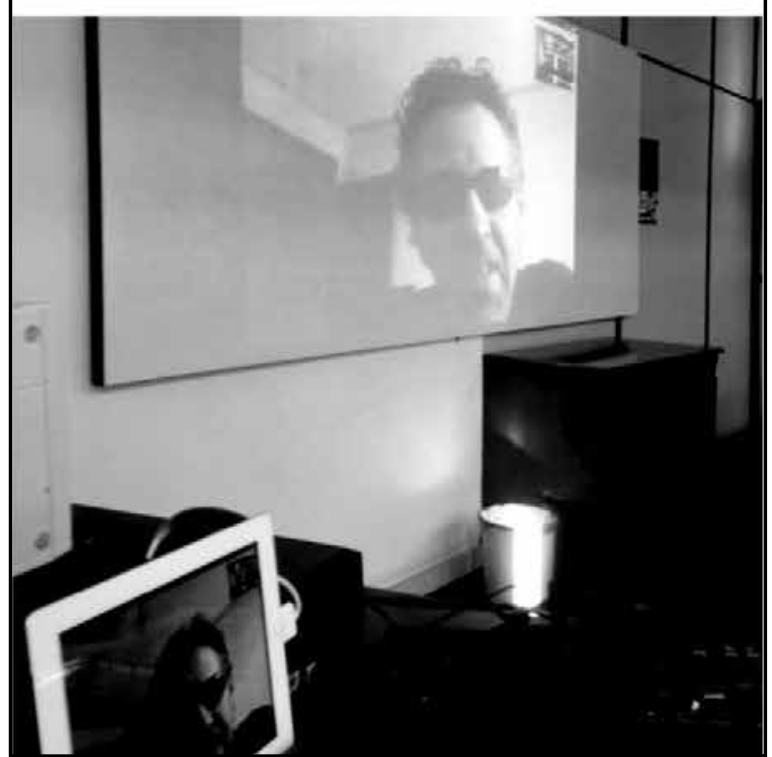

Fonte: Acervo particular da autora. 
No décimo quarto encontro - FASE IX - O TECELÃO - TECENDO COM A TEORIA, serão retomados os registros realizados no diário de viagem, no que se refere aos observáveis identificados por eles nos jogos (terceiro encontro), à luz das teorias estudadas e também trabalhadas nos encontros com as Pistas Vivas, a fim de identificar os conhecimentos construídos sobre as teorias até o momento. Será retomado ainda o "modelo" para avaliar jogos, para verificar a necessidade de ampliação.

Para os encontros subsequentes (mais quatro encontros) a proposta envolve jogar (testar) os jogos desenvolvidos pelos grupos nos projetos de aprendizagem. O que ficou definido com os estudantes é que iremos testar o "modelo" para avaliar jogos, criado por eles, em cada um dos jogos, bem como realizar observações dos sujeitos jogando, a fim de identificar elementos das teorias estudadas durante o semestre.

\section{Análises, Resultados e Considerações Finais}

Como a pesquisa está em desenvolvimento, as análises e resultados aqui apresentados se referem ao foco do artigo, ou seja, se vinculam ao objetivo de "compreender e discutir a relação design-cognição no processo da docência, num contexto de configuração de Espaços de Convivência Híbridos e Multimodais, na perspectiva da Gamificação".

Por se tratar de uma cartografia, a análise é do percurso realizado pelos sujeitos no processo do design da experiência, o qual teve como suporte o referencial teórico-metodológico apresentado.

Dessa forma, a partir da descrição do design da experiência, os principais resultados encontrados, até o momento, evidenciam que a relação design-cognição no processo da docência, principalmente vinculados à configuração de Espaços de Convivência Híbridos e Multimodais na perspectiva da Gamificação, ocorre na medida em que o docente configura, juntamente com os discentes, esses espaços de convivência, em que o outro é reconhecido como legítimo na interação e, portanto, alguém com quem também se aprende. Um espaço de convivência se configura no contexto educacional a partir de um espaço que é próprio do docente na interação com espaços próprios dos estudantes, os quais precisam ser transladados, num processo de permeabilidade constante, em que, em diferentes momentos, ambos são coaprendentes e coensinantes. Dessa forma, há possibilidade de transformação de ambos nessa convivência, que tem origem na construção colaborativa e cooperativa, e contribui significativamente para a aprendizagem. No caso do docente, essa aprendizagem, compreendida como atribuição de sentidos, ocorre no próprio processo da docência, enquanto essa se constitui. No entanto, isso só é possível se a relação educativa se constituir a partir do princípio da confiança e da legitimação do outro na interação.

Assim, a efetivação de um espaço de convivência híbrido e multimodal ocorreu a partir: 1) da integração de diferentes tecnologias analógicas e digitais, que favoreceram diferentes formas de comunicação e numa perspectiva multimodal (modalidade presencial física combinada com modalidade online, incluindo mobile learning, ubiquos learning e gamification learning); 2) do fluxo de comunicação e interação entre os sujeitos presentes nesse espaço híbrido e multimodal; 3) do fluxo de interação entre os sujeitos e os diferentes meios, ou seja, o próprio espaço híbrido e multimodal.

Dessa forma, um Espaço de Convivência Híbrido e Multimodal pressupõe, fundamentalmente, um tipo de interação que possibilite aos sujeitos configurá-lo de forma colaborativa e cooperativa, por meio do seu viver e do conviver.

Do ponto de vista da docência, no lugar de apresentar uma sequência de atividades relacionadas ao ensino sobre a cognição em jogos digitais, foi se construindo o design da experiência, apresentado anteriormente, que tem como objetivo principal provocar a exploração, a experimentação, a vivência dos conceitos teóricos a partir do próprio processo de aprendizagem dos estudantes, com os jogos digitais na educação, nas suas múltiplas perspectivas, quais sejam: jogos educacionais; jogos comerciais explorados em diferentes contextos de aprendizagem; a criação de jogos analógicos, digitais e híbridos; a construção de narrativas interativas; bem como a gamificação, num contexto que envolve o hibridismo e a multimodalidade, incluindo dispositivos móveis, geolocalização, 
realidade misturada, realidade aumentada, webconferência, Ambiente Virtual de Aprendizagem, Mídias Sociais, dentre outras. Essa exploração, experimentação e vivências dos estudantes provocam a produção de sentidos, a significação, portanto a aprendizagem necessária ao desenvolvimento das competências vinculadas à Atividade Acadêmica em questão.

Possibilita, da mesma forma, do ponto de vista dos docentes, a exploração, a experimentação e a vivência de novas possibilidades didático-pedagógicas, vinculadas a um contexto de hibridismo e multimodalidade, que provocam a produção de sentidos, a significação, portanto a aprendizagem necessária ao desenvolvimento das competências técnico-didático-pedagógicas relacionadas à docência na atualidade, propiciando, inclusive, a criação de novas metodologias, práticas e processos de mediação pedagógica num processo de ação-reflexão-ação docente, que se faz ao cartografar o processo. Assim, estar construtor atuante é fundamental para que o docente atribua sentidos a uma prática inovadora, justamente por "estar na situação" e, portanto, poder falar "de dentro", a partir do seu próprio processo de aprendizagem.

\section{REFERÊNCIAS}

BROWN, A. Design experiments: theoretical and methodological challenges in creating complex interventions in classroom settings. The Journal of the Learning Science, v. 2, n. 2, p.141-178, 1992.

COLLINS, A. Towards a design science education. In: SCANLON, E.; O'SHEA, T. (Ed.). New directions in educational technology. Berlin: Springer, 1992. p. 15-22.

DELEUZE, G.; GUATTARI, F. Rizoma. In: Mil platôs. Rio de Janeiro: Editora 34, 1995. p. 11-38.

EDELSON, D. C. Design research: what we learn when we engage in design. Journal of the Learning Sciences, v. 11, n. 1, p. 105-121, 2002.

FERREIRA, E. M. As narrativas interativas dos games: o cinema revisitado. ECO-PÓS, v. 9, n. 1, p.155-166, jan./ jul. 2006.

GALIAZZI, M. do C.; MORAES, R. Análise textual discursiva. Ijuí, RS: Editora UNIJUI, 2011.

HUIZINGA, J. Homo Ludens: o jogo como elemento da cultura. 4. ed. Tradução João Paulo Monteiro. São Paulo: Perspectiva, 1993.

KASTRUP, V. O método cartográfico e os quatro níveis da pesquisa-intervenção. In: CASTRO, L. R.; BESSET, V. (Org.). Pesquisa-intervenção na infância e adolescência. Rio de Janeiro: Nau, 2008. p. 465-489.

MAIA. M. M. B. A dimensão cognitiva da actividade do design: os designers nas organizações portuguesas de design industrial. 2011. Tese (Doutorado em Sociologia) - Universidade Técnica de Lisboa, Lisboa, 2011.

MATURANA, H. R. Da Biologia à Psicologia. Porto Alegre: Artes Médicas, 1998.

MATURANA, H. R.; REZEPKA, S. N. de. Formação humana e capacitação. Petrópolis, RJ: Vozes, 2000.

MATURANA, H. R.; VARELA, F. J. G. De máquinas e seres vivos: autopoiese - organização do vivo. Porto Alegre: Artes Médicas, 1997.

. Árvore do conhecimento: as bases biológicas da compreensão humana. São Paulo: Palas Athena, 2002.

McGONIGAL, J. Reality is broken: why games make us better and how they can change the world. Penguin Press HC, 2011.

PAPERT, S. A máquina das crianças: repensando a escola na era da informática. Porto Alegre: Artes Médicas, 1994.

PASSOS, E.; KASTRUP, V.; ESCÓSSIA, L. Pistas do método da cartografia: pesquisa-intervenção e produção de subjetividades. Porto Alegre: Sulina, 2012.

PIAGET, J. A formação do símbolo na criança: imitação, jogo e sonho imagem e representação. Rio de Janeiro: LTC, 1964. 
PIAGET, J. Desenvolvimento e aprendizagem. Traduzido por Paulo Francisco Slomp. In: LAVATTELLY, C. S.; STENDLER, F. Reading in child behavior and development. New York: Hartcourt Brace Jonovich. 1972. p. 7-19.

SACCOL, A. Z.; SCHLEMMER, E. ; BARBOSA, J. L. V. M-learning e U-learning: novas perspectivas da aprendizagem móvel e ubíqua. São Paulo: Pearson Education, 2011.

SCHLEMMER, E. O trabalho por projetos em educação a distância - uma parceria. In: CONGRESSO INTERNACIONAL DE EDUCAÇÃO A DISTÂNCIA, 6., 1999, Rio de Janeiro. Anais... Rio de Janeiro: ABED, 1999.

Projetos de aprendizagem baseados em problemas: uma metodologia interacionista/construtivista para formação de comunidades em ambientes virtuais de aprendizagem. In: CONGRESSO INTERNACIONAL DE INFORMÁTICA EDUCATIVA, 1., 2001, Madrid. Anais... Madrid: Universidad Nacional de Educación a Distância (UNED), 2001.

AVA: um ambiente de convivência interacionista sistêmico para comunidades virtuais na cultura da aprendizagem. 2002. 348 f. Tese (Doutorado em Informática na Educação) - Programa de Pós Graduação em Informática na Educação, Universidade Federal do Rio Grande do Sul, Porto Alegre, 2002.

. Metodologias para educação a distância no contexto da formação de comunidades virtuais de aprendizagem. In: BARBOSA, Rommel Melgaço. (Org.). Ambientes virtuais de aprendizagem. Porto Alegre, 2005. p. 29-49.

ECODI - a criação de espaços de convivência digital virtual no contexto dos processos de ensino e aprendizagem em metaverso. Cadernos IHU Ideias (UNISINOS), v. 6, p. 1-32, 2008.

Telepresença. Curitiba: IESDE Brasil, 2009.

Espaço de convivência digital virtual nos programas de pós-graduação (Stricto Sensu) - ECODI-PPGs UNISINOS: uma proposta para a formação de professores-pesquisadores. Bolsa PQ. CNPq, 2010a.

. Anatomia no metaverso Second Life: uma proposta em i-Learning. Edital FAPERGS 006/2010 Programa Pesquisador Gaúcho - PqG. FAPERGS, 2010b.

SCHLEMMER, E. Gamificação em espaços de convivência híbridos e multimodais: uma experiência no ensino superior (cognição em jogos digitais). Projeto de Pesquisa. Edital MCTI/CNPQ/MEC/CAPES nº 43/2013. São Leopoldo, 2013.

SCHLEMMER, E.; TREIN, D. Projetos de aprendizagem baseados em problema no contexto da web 2.0: possibilidades para a prática pedagógica. Revista e-Curriculum (PUCSP), São Paulo, v. 4, n. 2, jun. 2009. Disponível em: <http://revistas.pucsp.br/index.php/curriculum/article/viewFile/3225/2147>. Acesso em: 15 ago. 2014.

SCHLEMMER, E.; SILVA, J. F; SACCOL, A. I. da C. Z. METARIO - Rede de pesquisa e formação docente em metaversos: desenvolvimento de competências para a docência em administração. Edital Pró-Administração 09/2008. CAPES, 2008.

SCHLEMMER, E. Et al. ECoDI: a criação de um espaço de convivências digital virtual. In: SIMPÓSIO BRASILEIRO DE INFORMÁTICA NA EDUCAÇÃO (SBIE), 17., 2006. Anais... Brasília. Brasília: Universidade de Brasília/Universidade católica de Brasília, 2006.

SCHÖN, D. A. Educando o profissional reflexivo. Um novo design para o ensino e a aprendizagem. Porto Alegre: Artes Médicas Sul, 2000.

VARELA, F. J. Conocer. Las ciencias cognitivas: tendencias y perspectivas: cartografia de las ideas actuales. 4. ed. Barcelona: Gedisa Editorial, 2005.

VYGOTSKY, V. S. A formação social da mente. O desenvolvimento dos processos psicológicos superiores. São Paulo: Martins Fontes, 1994.

ZICHERMANN, G.; LINDER, J. Game-based marketing: inspire customer loyalty through rewards, challenges, and contests. Wiley, 2010. 